\title{
Editorial
}

\section{Exclusive Breastfeeding - Practices, Problems and Promises}

\author{
Received: August 29, 2018 Accepted: August 31, 2018 \\ doi: http://dx.doi.org/10.3329/jemc.v8i3.38360
}

Exclusive breastfeeding is the best recommended infant feeding method for the first six months of life and has a protective effect against child morbidity and mortality ${ }^{1}$, but the reduction in the rate of the EBF is a serious problem, especially in developing countries like Bangladesh. ${ }^{2}$ Bangladesh is traditionally a breastfeeding country, but it is strange to observe that the majority of protein energy malnutrition (PEM) cases present in less than one year of age. This picture reflects the failure of exclusive breastfeeding (EBF) practice in the country. ${ }^{3}$

According to the report published by UNICEF updated in July 2017 , only $51 \%$ of our newborns start breastfeeding within one hour of birth. ${ }^{4}$ The report is similar to the report published in 2014 by Bangladesh Demographic and Health Survey (BDHS). ${ }^{5}$ The rate of exclusive breastfeeding at 5 months completion was 55\% and continued breast feeding (along with complementary diets) rate was $34.5 \%$, in 19-24 months of age. ${ }^{3}$ Although the prevalence of any breastfeeding in Bangladesh is high (99\%), low prevalence of exclusive breastfeeding and a high prevalence of prelacteal feeding (32\%) are the major barriers to achieve the recommendations of the Global Strategy for Infant and Young Child Feeding (IYCF). ${ }^{6}$

EBF rates have been stagnated over last two decades (46\% in 1994 and $55 \%$ in 2014). ${ }^{5}$ Not only in Bangladesh, this is a concern worldwide. Different studies and systematic reviews have been conducted to evaluate the causes of non-adherence to EBF. Barriers to EBF have been categorised into three domains - maternal issues (prenatal barriers), barriers encountered on the first day including initiating and establishing EBF and barriers encountered in maintaining EBF over the first 6 months of life. ${ }^{7,8}$

Among the antenatal factors, most significant one is lack of attendance at antenatal care (ANC) that offers an opportunity to counsel women on EBF, among other health topics. Poor maternal knowledge on EBF including BF initiation, lack of intention to practice exclusive breastfeeding has been found to be significantly related. ${ }^{8}$ A part of these may be attributed to deep-rooted traditional practices, low level of literacy and the low utilisation of health facilities. ${ }^{9} \mathrm{On}$ the other hand, educated women are aware of BF, but not aware of what is meant by exclusive and what is the duration of EBF and they resorted to other modes of feeding. This highlights the necessity that knowledge should be translated into practice by reinforcement by the health worker. The mother along with family members should be counselled antenatally about colostrum, normal delay in letdown reflex, EBF, and neonatal behaviour.

Barriers to exclusive breastfeeding on the first day of life are delivery outside a health facility, delivery by caesarean section and delayed initiation of breastfeeding. Babies born by caesarean section are given prelacteal feeds more often and have delayed first breastfeed and given less number of breastfeeds in the first 24 hours. ${ }^{10}$ Offering prelacteal feeds makes the mother reluctant to take the trouble of BF in the postpartum illnesses. This in turn reduces suckling the breast and delays letdown reflex. Sometimes it has been seen that on hospital delivery the health care providers rather had advised for formula milk.

While assessing barriers to maintain exclusive breastfeeding in the first six months of life, majority of mothers claim that they started breast milk supplement because of insufficient breast milk production for which the baby always remain hungry and cries. Moreover, mother thinks that the baby is not growing well. This psychosocial attitude still remains the top most cause of breast milk supplements. ${ }^{3}$ The responsible factor for this perception is inadequate counselling during ANC. Maternal employment and early weaning in preparation to return to work also contribute much in non-adherence to EBF. Breast problems like mastitis, breast engorgement and cracked or inverted nipples and other maternal sicknesses are common causes of giving supplementary feeding. Although most of the mothers know about duration and importance of exclusive breastfeeding, knowledge of proper positioning and 
attachment is lacking in majority of them. The social barrier includes lack of family support, influences of mother-in-laws and other close relatives. ${ }^{11,12}$

Promising interventions that can help tremendously are strengthening health workers' skill at health facilities and Baby-Friendly Hospital Initiative. Health workers should play a critical role in EBF counselling and should be equipped with the necessary skills to address breastfeeding problems during ANC and postnatal care, especially in light of recent WHO ANC guidelines. ${ }^{8,13}$ Immunisation and ANC visits in specific, should be utilised for promoting EBF practices and there is no alternative to appropriate counselling.

After delivery, help should be offered to the mother for starting breastfeeding as early as within one hour, to continue EBF up to 6 months and till 2 years. Awareness level needs to be improved by increasing education level of mother and family by mass campaigning through electronic and print mass media.

Improving knowledge and counselling skills of health workers to address breastfeeding problems and increasing community support for breastfeeding are critical to the success of EBF program. Actions are needed to enact supportive legislation and strict regulations on marketing of breastmilk substitutes, paid maternity leave and breastfeeding breaks for working mothers.

\section{Prof. Shaheen Akter}

Department of Paediatrics

Enam Medical College \& Hospital, Savar, Dhaka Email: shaheenssr7@yahoo.com

\section{References}

1. Ruel MT, Brown KH, Caulfield LE. Moving forward with complementary feeding: indicators and research priorities. Food consumption and nutrition division Discussion paper 146. International Food Policy 2003.

2. Islam K, Samad N, Haque MM, Sadia A, Adhikary AC, Ahmed N. Constraints of exclusive breastfeeding practice among breastfeeding mothers of Dhaka slums. J Nutr Food Sci 2017; 7: 6-9.

3. Salim M, Mita SA, Uddin MN, Jahan NWB, Ali $\mathrm{MZ}$, Rahman MM et al. Infant and young child feeding practices up to two years of age and their nutritional status. Bangladesh Med J 2014; 41:14-20.

4. UNICEF - nutrition. Available at: https://www. unicef.org/nutrition/index_100585.html. Accessed August 2018.

5. The DHS program - Bangladesh: DHS, 2014 - Final report. Available at: https://dhsprogram.com/pubs/ pdf/FR311/FR311.pdf. Accessed August 2018.

6. Mihrshahi S, Ichikawa N, Shuaib M, Oddy W, Ampon R. Prevalence of exclusive breastfeeding in Bangladesh and its association with diarrhoea and acute respiratory infection: results of the multiple indicator cluster survey 2003. J Health Popu Nutr 2007; 25: 195-204.

7. US Agency for International Development (2016). Acting on the Call. Ending preventable child and maternal deaths: a focus on equity. Washington, DC: USAID.

8. Justine AK, Elizabeth LC, Hallie D, Cyril E. Addressing barriers to exclusive breast-feeding in lowand middle-income countries: a systematic review and programmatic implications. Pub Health Nutr 2017; 20: $3120-3131$.

9. Tiwari R, Mahajan PC, Lahariyaa C. The determinants of exclusive breastfeeding in urban slums: a community based study. Journal of Tropical Pediatrics 2009; 55: 49-54.

10. Banapurmath CR, Selvamuthukumarasamy A. Breastfeeding and the first breastfeeds-correlation of initiation pattern to mode of delivery in 1279 hospital delivered babies. Indian Paediatrics 1995; 32: 1299-1302.

11. Sharmin L, Chowdhury MAKA, Khatun S, Ahmed $\mathrm{N}$. Barriers of exclusive breastfeeding among urban mothers. J Enam Med Col 2016; 6: 88-92.

12. Chandrashekhar TS, Joshi HS, Binu VS, Shankar PR, Rana MS, Ramachandran U. Breast-feeding initiation and determinants of exclusive breast-feeding - a questionnaire survey in an urban population of western Nepal. Pub Health Nutr 2006; 10: 192-197.

13. World Health Organization (2016). WHO recommendations on antenatal care for a positive pregnancy experience. Geneva: WHO. 